\title{
Identification of Candidate Genes and Proteins Related to the Production of ROS in Korla Pear Fruit
}

\author{
Aisajan Mamat ${ }^{*}$, Kuerban Tusong, Juan Xu, Jixun Wang \\ Institute of Horticultural Crops, Xinjiang Academy of Agricultural Sciences, Urumqi, China \\ Email address: \\ 103326533@qq.com (A. Mamat) \\ ${ }^{*}$ Corresponding author \\ To cite this article: \\ Aisajan Mamat, Kuerban Tusong, Juan Xu, Jixun Wang. Identification of Candidate Genes and Proteins Related to the Production of ROS in \\ Korla Pear Fruit. Plant. Vol. 9, No. 1, 2021, pp. 1-9. doi: 10.11648/j.plant.20210901.11
}

Received: December 22, 2020; Accepted: January 12, 2021; Published: January 18, 2021

\begin{abstract}
Korla fragrant pear (P. sinkiangensis Yü) is a landrace selected from a hybrid pear species of Xinjiang Autonomous Region in China. However, recently the formation of rough skin fruits is one of the main factors reducing fruit quality. In this study, parallel analyses of transcriptomic and proteomic data of Korla pear fruits from the three developmental stages (20,50 and 80 days after flowering, DAF) were carried out by using RNA sequencing (RNA-seq) and tandem mass tags technology (TMT), to identify differential genes and proteins that may regulate reactive oxygen species (ROS) generation during stone cell differentiation period. In total, 42893 transcripts and 7904 proteins were acquired. Among them, 74 differentially expressed genes (DEGs) and 40 correlated proteins were identified as ROS related genes and proteins, including 15 differentially accumulated proteins (DAPs). These include genes and proteins related to the ROS production in the apoplast (24 DEGs and seven DAPs), mitochondria (23 DEGs and two DAPs), peroxisome (10 DEGs and four DAPs), and during fatty acid degradation (15 DEGs and two DAPs), respectively. All of DEGs and DAPs that related to apoplastic ROS production and some of DEGs and DAPs that related to ROS production in peroxisome and fatty acid metabolism pathways were abundantly expressed during the critical period of stone cell differentiation (20 DAF). To sum up, apoplast might be the main source of ROS production that participate in the process of stone cell differentiation in pear fruits. In addition, peroxisome and fatty acid metabolism pathways also produce certain amount of ROS during this process.
\end{abstract}

Keywords: Korla Pear, Fruit Development, Transcriptome, Proteome, Reactive Oxygen Species, Stone Cells

\section{Introduction}

Korla fragrant pear (Pyrus sinkiangensis Yü) is one of the characteristic fruit trees in Xinjiang, China. Korla fragrant pear is distinctive for its aroma, rich juicy flesh and crispy texture. However, in recent years, the content of stone cells in Korla pear fruits has increased and causing the formation of rough skin on fruit surface, which leads to degradation of varieties and the reducing of fruit quality. Previous studies showed that the process of stone cell differentiation is in nature a process of secondary thickening of cell walls $[1,2]$. Lignin is the main structural component of secondary of cell wall, so as the stone cells [3]. After being synthesized in the cytoplasm, the lignin monomers are transported through the plasma membrane to the cell walls, and polymerizes into lignin under the action of $\mathrm{O}_{2}^{--}$dependent laccase (LAC) and $\mathrm{H}_{2} \mathrm{O}_{2}$ dependent peroxidase (PRX) [4], reactive oxygen species (ROS) play a critical role in this process [5].

Recently, more researchers have started to focus on the role of ROS in fruit development, maturation and senescence of several plants [6-10]. It is also reported that occurrence of "Hard end fruits" in apple and pear is also closely related to the metabolism of ROS [11-13]. Our previous work indicated that accumulation of ROS and cell apoptosis (also called programmed cell death, PCD) occurred along with the differentiation of stone cells, the period of PCD and stone cell differentiation overlaps with ROS accumulation. ROS is the main stress factor leading to PCD. Therefore, we presumed that ROS may act as a signal molecule to activate PCD in some specific cells, lignin deposition in the secondary walls of cells that went through apoptosis to form sclerotic cells. In order to reveal this scientific inference, in this study, parallel analyses of the transcriptome and proteome of Korla pear fruits from the three developmental 
stages were carried out using RNA-seq and TMT technologies, aiming to explore the source of ROS in fruit pulps during the critical period of stone cell differentiation. ROS related candidate genes and proteins gained through this study would help us understand the underlying function of these genes and proteins in the process of stone cell differentiation, and would shed a light on the molecular mechanism of stone cell differentiation in Korla pear fruit.

\section{Materials and Methods}

\subsection{Materials}

The fruit samples were collected at the different stages of development from 15-year-old Korla pear trees grown in an orchard at Korla (Xinjiang, China). Pulps were scooped out from the fruits 20,50 and 80 days after flowering (DAF), representing prime, late and stationary stages of stone cell differentiation, respectively. Samples were flash frozen in liquid nitrogen immediately, and then stored at $-80^{\circ} \mathrm{C}$ for further study. For samples of early developmental stage (20 and 50 DAF), fifteen fruits were gathered from five trees for each biological replicate, and ten fruits were collected from five trees for each biological replicate for samples of late developmental stage.

\subsection{Transcriptome Data Analysis}

Total RNA was isolated from the pulps using TRlzol® reagent. RNA purity and concentration were assessed using the NanoPhotometer ${ }^{\circledR}$ spectrophotometer (IMPLEN, CA, USA). Sequencing libraries were generated using NEBNext ${ }^{\circledR}$ UltraTM RNA Library Prep Kit for Illumina ${ }^{\circledR}$ (NEB, USA). Illumina-based RNA sequencing was performed on the Hiseq ${ }^{\text {TM }} 4000$ platform. After removing the low quality reads, the filtered clean reads were mapped to the Pyrus bretschneideri reference genome. The uniquely mapped reads were used to calculate FPKM (fragments per kb per Million reads) for the gene expression quantification. Genes with an adjusted $P$-value $<0.05$ and $\mid \log 2$ (fold change) $\mid>1$ were assigned as differentially expressed. The transcriptome sequencing data supporting the results of this work can be accessed in the Short Read Archive (SRA) of The National Center for Biotechnology Information (NCBI) with the accession number SRX7122321 - SRX7122329.

\subsection{Proteomic Data Analysis}

Protein concentration was determined with Bradford assay, precisely $0.1 \mathrm{mg}$ of protein was digested with Trypsin Gold (Promega) at $37^{\circ} \mathrm{C}$ for $16 \mathrm{~h}$. After trypsin digestion, peptide was desalted with $\mathrm{C} 18$ Cartridge to remove the high urea, and desalted peptides were dried by vacuum centrifugation. Desalted peptides were labeled with TMT6/10-plex reagents. Shotgun proteomics analyses were performed with an EASY-nLCTM 1200 UHPLC system (Thermo Fisher) coupled to an Orbitrap Q Exactive HF-X mass spectrometer (Thermo Fisher) operating in the data-dependent acquisition (DDA) mode. Differentially accumulated proteins (DAPs) were screened based on $\mathrm{P}<0.05$ and $|\log 2 \mathrm{FC}|>0.585$. GO and KEGG enrichment analysis were performed to identify the major biological functions and important metabolic pathways involved in DAPs. The raw data of proteome sequencing support the results of this work can be accessed in ProteomeXchange repository with the accession number PXD018829.

\subsection{Validation of the RNA-seq Results by qRT-PCR}

Eight potential genes relating to ROS production in Korla pear fruits were randomly selected for verification of expression levels by using quantitative real-time PCR. The primer sequences were designed using Oligo 7.0 software package. The specificity of the primer sets was examined by running the PCR products on agarose gel to ensure a single band amplification. About $1 \mu \mathrm{g}$ of total RNA was used for the synthesis of cDNA with reverse transcriptase RR037A (TAKARA, USA). qRT-PCR was performed in $20 \mu \mathrm{l}$ system, containing $1 \mu \mathrm{l}$ of forward and reverse primers of each, SYBR Green Real-Time PCR Master Mixes (Invitrogen, USA) and 1 $\mu l$ of cDNA template on STEP ONE PLUS ${ }^{\text {TM }}$ Real-Time PCR System (Applied Biosystems, USA). The cycling conditions were as follows: $95^{\circ} \mathrm{C}$ for $15 \mathrm{~min}$ followed by 40 cycles of $95^{\circ} \mathrm{C}$ for $10 \mathrm{~s}, 58^{\circ} \mathrm{C}$ for $20 \mathrm{~s}$, and $72^{\circ} \mathrm{C}$ for $20 \mathrm{~s}$. Each sample had three individuals as replicates. The expression level of each gene was normalized to that of Tubulin, relative gene expression level was calculated with the method of $2^{-\Delta \Delta \mathrm{Ct}}[14]$.

\subsection{Data Analysis}

Microsoft Office Excel 2010 and Graphpad Prism 7.0 softwares were used for all data processing, statistical significance of differences analyzed using one-way ANOVA followed by Tukey's post hoc test with a significance level of $0.05(\mathrm{P}<0.05)$. In addition, all the DEGs and DAPs data are standardized by converting all data to values between 0 and 1 by the minimum maximum normalization method.

\section{Results}

\subsection{Transcriptome and Proteome Data Analysis}

In order to identify the candidate genes and proteins which were related to ROS production in Korla pear fruit, transcriptome and proteome analysis were performed on fruit samples from three different developmental stages. In total, 42893 transcripts and 7904 proteins were acquired in pear fruit. Among of them, 66 DEGs and 37 correlated proteins were identified as ROS related genes or proteins, including 11 DAPs (Figure 1a). These candidate genes and proteins were involved in the production of extracellular ROS (24 DEGs and seven DAPs), mitochondrial ROS (18 DEGs and 0 DAP), peroxisome ROS (10 DEGs and two DAPs), and ROS production during fatty acid oxidation (14 DEGs and two DAPs), respectively. To verify the reliability of RNA-seq results, eight genes related to ROS production were randomly selected for quantitative real-time PCR validation. As it shown in Figure 1b, the real-time PCR expression patterns of 
these genes at different developmental stages in pear fruit were highly consistent with the expression tendency of RNA-seq results, which showed the reliability of RNA-seq analysis.

(a)

(b)
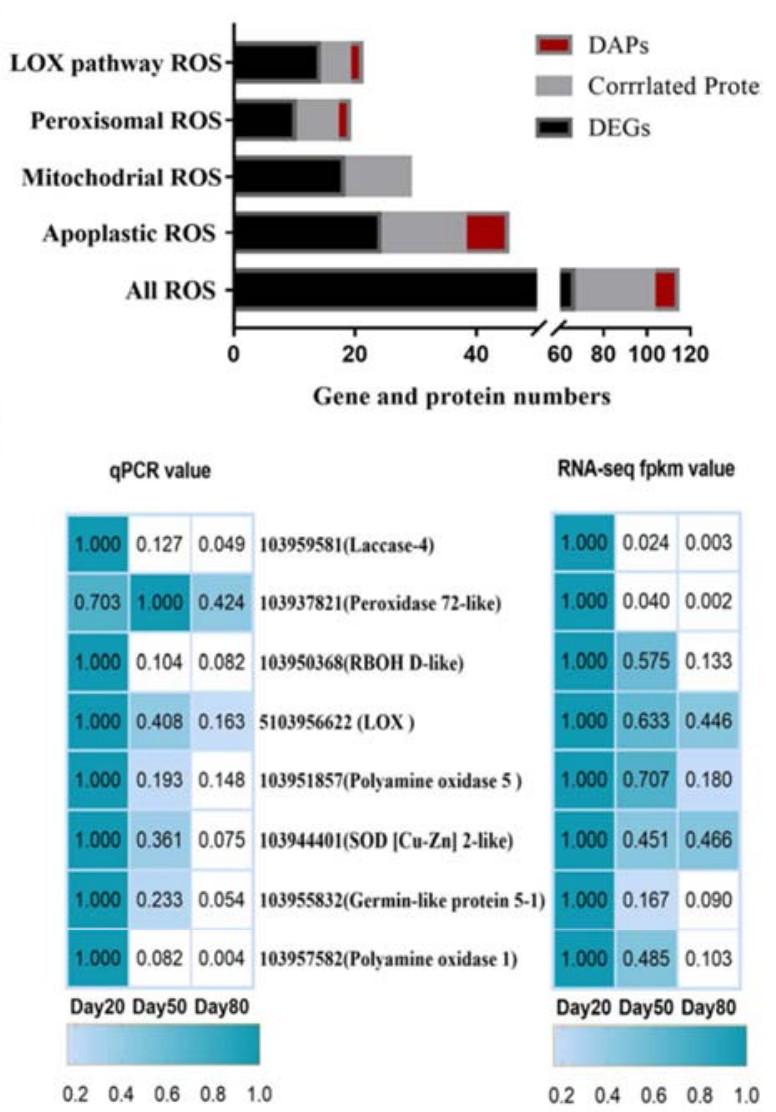

Figure 1. ROS related genes and proteins in Korla pear pulp. (a) shows the number of DEGs and correlated proteins, (b) indicated the validation of $R N A$-seq analysis by quantitative real-time PCR. Heat maps were produced using standardized figures that were transformed to a value between 0.0 and 1.0 by Min-Max normalization method.

\subsection{DEGs Related to Apoplastic ROS Production in Pear Fruit}

In plants and other eukaryotes, many enzymes participate in or regulate the apoplastic ROS generation. These ROS in turn are involved in cell signal transduction as signal molecules, and also participate in cell wall metabolism. The differential expression analysis in this work showed that 27 DEGs encode enzymes that are related to apoplast ROS production. Among them, five genes coding NADPH oxidase (also known as respiratory burst oxidase homologs, RBOHs), nine genes encode peroxidase (PRX) on cell wall, five of them encode polyamine oxisase (PAO), one gene encode SOD and four of genes encode oxalate oxidase (or Germin). As it shown in the Figure 2, most of the genes related to apoplastic ROS generation were highly expressed in the early stage of fruit development, expression levels were gradually decreased along with fruit-development. The result is consistent with the changes of stone cells in pear fruit $[15,16]$, indicating that genes related to the production of ROS may participate in the differentiation of stone cells. However, some of these genes, such as $R B O H C$-like, $P R X$ 1-like and some $P R X$ s showed an opposite tendency in expression compared to other genes, indicating that these genes may play a role in the late stage of fruit development and involved in the regulation of cell wall loosening during fruit ripening.

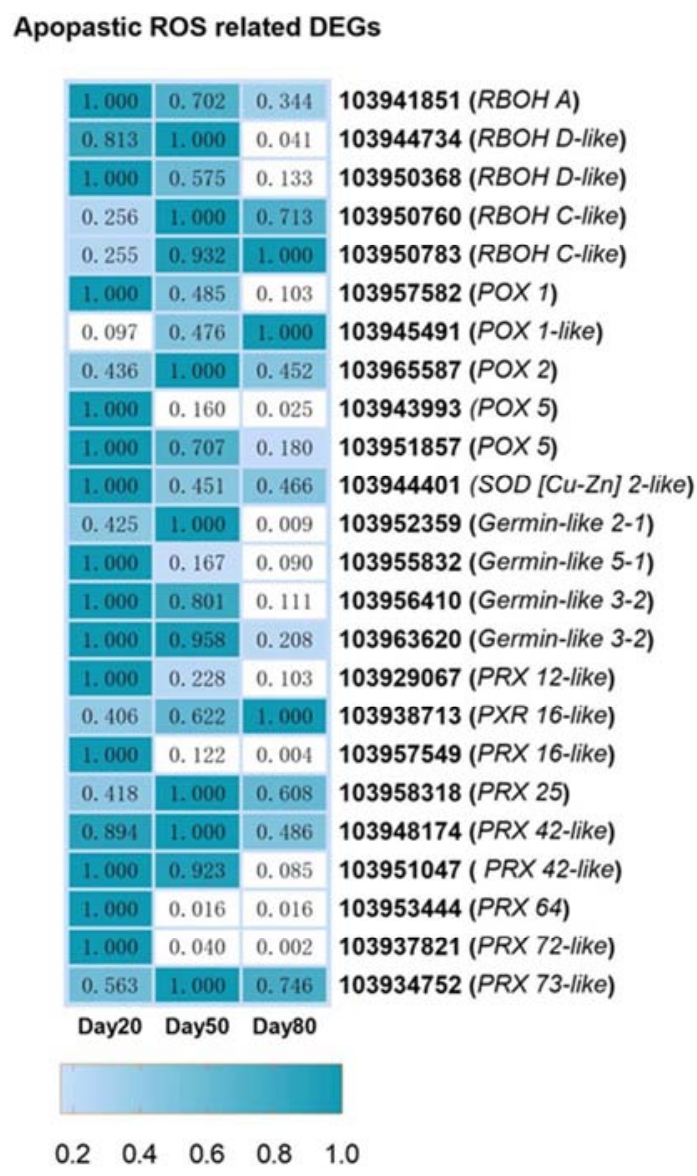

Figure 2. DEGs related to production of apoplastic ROS in Korla pear pulp. Heat maps were produced using standardized figures that were transformed to a value between 0.0 and 1.0 by Min-Max normalization method.

\subsection{DEGs Related to Peroxisome ROS Production in Pear Fruit}

Acyl coenzyme A oxidase (ACOX) and glycolate oxidase (GOX) are main enzymes producing ROS in Peroxisome. ACOX mainly catalyzes the $\beta$-oxidation of fatty acids to produce $\mathrm{H}_{2} \mathrm{O}_{2}$, while $\mathrm{GOX}$ continuously catalyzes the oxidation of acetic acid and glycolic acid into glyoxylic acid and $\mathrm{H}_{2} \mathrm{O}_{2}$. In this work, we have identified 5 DEGs encoding ACOX and 5 DEGs encoding GOX, respectively (Figure 3). The differentially expressed $G O X S$ were highly up regulated at early stage of fruit development (20 DAF), and then decreased gradually. The differential expression fold change of these genes in different stages of fruit development range from 1.75 folds to 9.99 fold. Among the DEGs encoding ACOX, except for one transcript (Entrez ID: 103967278), expression levels of other four DEGs were low in early fruits, as the fruits growing the expression levels of these genes gradually reached their picks in the late stage (80 DAF), the expression 
fold change of these genes in different stages ranged from 2.63 to 10.43 . These results indicate that ROS produced in peroxisome during the critical period of stone cell differentiation (0 to $50 \mathrm{DAF}$ ) were mainly derived from the process of glycolic acid cycle (respiration process), while ROS produced in peroxisome in late stage of fruit development were mainly comes from the $\beta$-oxidation of fatty acids, which is closely related to the conversion of fat to sugar and aroma components, thus this process may be related to the accumulation of sugars and aroma components in pear fruits.

\begin{tabular}{|c|c|c|c|}
\hline \multicolumn{3}{|c|}{ Peroxisomal ROS } & \multirow[b]{2}{*}{$103936200(G O X)$} \\
\hline 1.00 & 0.21 & 0.11 & \\
\hline 1.00 & 0.18 & 0.12 & 103939610 (GOX) \\
\hline 1.00 & 0.52 & 0.40 & 103945960 (GOX-like) \\
\hline 1.00 & 0.46 & 0.48 & 103951291 (GOX1) \\
\hline 1.00 & 0.54 & 0.56 & 103966866 (GOX 4-like) \\
\hline 1.00 & 0.15 & 0.07 & 103967278 (ACOX 1-like) \\
\hline 0.38 & 0.65 & 1.00 & 103956148 (ACOX) \\
\hline 0.07 & 0.30 & 1.00 & 103937274 (ACOX) \\
\hline 0.36 & 0.54 & 1.00 & 103966317 (ACOX) \\
\hline 0.24 & 0.33 & 1.00 & 103967012 (ACOX) \\
\hline Day20 & Day50 & Day 80 & \\
\hline
\end{tabular}

Figure 3. DEGs related to production of peroxisome ROS in Korla pear pulp. Heat maps were produced using standardized figures that were transformed to a value between 0.0 and 1.0 by Min-Max normalization method.

\subsection{DEGs Related to ROS Production in Lipoxygenase Pathway}

Lipoxygenase (LOX) catalyzes the process of oxidation of fatty acids, and produce some free radicals, this is another way of ROS production in plants. LOX can be divided into 9-LOXs and 13-LOXs due to their different catalytic positions. In this study, we have identified 15 DEGs encoding LOXs from pear pulp transcriptome data. Among of them, 10 genes were annotated as 9-LOXs, 4 genes were annotated as 13-LOXs, and one gene was not clearly classified. As it has shown in figure 4 , the expression patterns of these LOX genes can be divided into two categories. The first type contains 11 genes, with the highest expression level in the early stage of fruit development, and the lowest in the late stage. The difference in expression levels of these genes varies between 2.2 to 100 times during the fruit development stages, these indicates that these genes may regulate ROS produced in the LOX pathway during stone cell differentiation in pear fruits. Rest of the three LOX genes were significantly up regulated in the late stage of fruit development rather than in early fruits, with expression levels ranging from 2.0 folds to 15.2 folds among different stages. Like $A C O X s$, these genes may be involve in the formation of aroma and other flavor substances in fruit ripening process.

Fatty acid oxidation

\begin{tabular}{|c|c|c|c|}
\hline 1.00 & 0.11 & 0.02 & 103935971 (Linoleate 9S-lipoxygenase 5) \\
\hline 1.00 & 0.05 & 0.01 & 103954602 (Linoleate 13S-lipoxygenase 2) \\
\hline 1.00 & 0.08 & 0.02 & 103954616 (Linoleate 13S-lipoxygenase 2) \\
\hline 1.00 & 0.40 & 0.13 & 103955720 (Linoleate 9S-lipoxygenase 5) \\
\hline 1.00 & 0.63 & 0.45 & 103956622 (Linoleate 9S-lipoxygenase 5) \\
\hline 0.16 & 1.00 & 0.01 & 103941411 (Linoleate 13S-lipoxygenase 3) \\
\hline 0.81 & 1.00 & 0.54 & 103954903 (Linoleate 13S-lipoxygenase 2) \\
\hline 1.00 & 0.57 & 0.01 & 103955722 (Linoleate 9S-lipoxygenase 5) \\
\hline 1.00 & 0.56 & 0.04 & 103955797 (Linoleate 9S-lipoxygenase 5) \\
\hline 1.00 & 0.89 & 0.14 & 103965340 (Linoleate 9S-lipoxygenase 5) \\
\hline 1.00 & 0.39 & 0.08 & 103965359 (Linoleate 9S-lipoxygenase 5) \\
\hline 0.06 & 0.94 & 1.00 & 103965343 (Linoleate 9S-lipoxygenase 5) \\
\hline 0.49 & 0.57 & 1.00 & 103965360 (Linoleate 9S-lipoxygenase 5) \\
\hline 0.49 & 1.00 & 0.88 & 103965342 (Linoleate 9S-lipoxygenase 5) \\
\hline Day20 & Day50 & Day80 & \\
\hline 0.2 & 0.6 & 0.8 & \\
\hline
\end{tabular}

Figure 4. Expression of LOX genes in Korla pear pulp. Heat maps were produced using standardized figures that were transformed to a value between 0.0 and 1.0 by Min-Max normalization method.

\subsection{DEGs Related to Mitochondrial ROS Production in Pear Fruit}

Mitochondria are the main place of ROS production in normal respiration process in plant cells, mainly caused by the leakage of singlet oxygen from complex I (NADH-q reductase, known as NADH dehydrogenase) and complex III (cytochrome reductase). In this work, we have identified 23 DEGs which are related to mitochongerial ROS production. Among them, 13 genes encode different subunits of complex I, including NADH dehydrogenase [ubiquinone] flavoprotein (NDUFV) encoded by a nuclear gene with the function of NADH driven oxidative dehydrogenation, NADH dehydrogenase (NADH) ferrithionein (NDUFS) with the function of electron transportation, protective NADH dehydrogenase [ubiquinone] $\alpha / \beta$ subcomplex subunits with the function of maintaining the structural integrity of complex I, one ubiquinol cytochrome-c reductase complex assembly factor 1 (UQCC1), two mitochondrial SOD enzymes (Figure 5).

As it shown in the figure, the expression levels of genes encoding NDUFV, NDUFS and UQCC in late developmental stage pear fruit is higher than that of in the early stages, while the genes encoding the structural integrity related subunit proteins of complex I were highly expressed in early stage of fruit development, indicating that the electron transfer efficiency of mitochondrial respiratory chain was low in the early stage, and some electron leakage may occur. However, at different stages, the differential expression levels of these genes were not obvious. Moreover, DEGs encoding some subunit proteins responsible for electron transport (NDUFS7) and most of the subunits related to the structural integrity of 
complex I, were highly expressed in the early fruits. Therefore, the effect of mitochondrial ROS to the differentiation of stone cells was not significant, which might be involved in other biological processes in fruit development.

\begin{tabular}{|c|c|c|c|}
\hline \multicolumn{3}{|c|}{ Mitochodrial ROS related DEGs } & \multirow[b]{2}{*}{103928926 (NDUFV2) } \\
\hline 0.61 & 0.74 & 1.00 & \\
\hline 0.72 & 0.72 & 1.00 & 103961498 (NDUFV1) \\
\hline 0.70 & 0.68 & 1.00 & 103937079 (NDUFA9-like) \\
\hline 0.93 & 0.70 & 1.00 & 103927971 (NDUFA9-like ) \\
\hline 1.00 & 0.53 & 0.82 & 103964114 (NDUFA8-B-like) \\
\hline 0.78 & 0.70 & 1.00 & 103955336 (NDUFA13-A) \\
\hline 0.57 & 1.00 & 0.94 & 103952228 (NDUFA13-B) \\
\hline 1.00 & 0.60 & 0.84 & 103951425 (NDUFA2-like) \\
\hline 1.00 & 0.68 & 0.93 & 103964114 (NDUFB9-like) \\
\hline 0.09 & 0.88 & 1.00 & 103951264 (NDUFS4) \\
\hline 1.00 & 0.69 & 0.65 & 103951932 (NDUFS7) \\
\hline 0.60 & 0.65 & 1.00 & 103959447 (NDUFS1) \\
\hline 0.59 & 0.66 & 1.00 & 103959889 (NDUFS1) \\
\hline 0.78 & 0.67 & 1.00 & 103963133 (NDUFS8) \\
\hline 0.34 & 0.99 & 1.00 & 103963992 (NDUFS4) \\
\hline 0.57 & 0.74 & 1.00 & 103952756 (UQCC1) \\
\hline 0.73 & 0.73 & 1.00 & $103953755(S O D)$ \\
\hline 0.76 & 0.62 & 1.00 & $103953790(S O D)$ \\
\hline Day20 & Day50 & Day80 & \\
\hline 0.2 & 0.6 & 0.8 & 1.0 \\
\hline
\end{tabular}

Figure 5. Expression of mitochondrial ROS production genes in Korla pear pulp. Heat maps were produced using standardized figures that were transformed to a value between 0.0 and 1.0 by Min-Max normalization method.

\subsection{Core DEGs and DAPs Related to ROS Production in Stone Cell Differentiation of Pear Fruit}

By analyzing the correlation between transcriptome and proteome data of pear fruit pulp, 13 genes related to ROS production were identified as up regulated at both transcription and protein levels (Figure 6). These DEGs and DAPs were mainly enriched in the apoplast ROS production pathway (four genes encode PRX enzymes, two gene encode $\mathrm{RBOH}$ proteins and one gene encode PAO enzyme), peroxisome ROS production pathways (two genes encode GOX and ACOX enzymes, respectively), mitochondrial ROS production pathways (two genes encode NDUFA subunit of complex I) and fatty acid metabolism pathway (two genes encode LOX enzyme). Among them, the number of genes and proteins related to apoplast ROS production was the largest, and they were highly expressed in key stage of fruit stone cell differentiation, indicating that these genes were closely related to stone cell differentiation. In addition, two genes related to peroxisomal ROS production and one gene related to ROS production in fatty acid metabolism pathway were also expressed at a high level during the critical period of stone cell differentiation, and showed a high level of expression fold change during deferent developmental stages, this indicates that these genes and proteins also play an important role in stone cell differentiation.

The expression levels of genes and proteins related to the structural stability of mitochondrial complex I were low in the early stage of fruit development, but high in the late stage, which indicated that the electron transfer efficiency of mitochondria was low during the period of stone cell differentiation, and electron leakage might occur. However, there was no significant difference in the expression levels of ROS related genes or proteins in fruits between different periods, indicating that mitochondrial ROS may not be essential for the differentiation of stone cells in the early stage of fruit development.

\section{Transcriptome data}

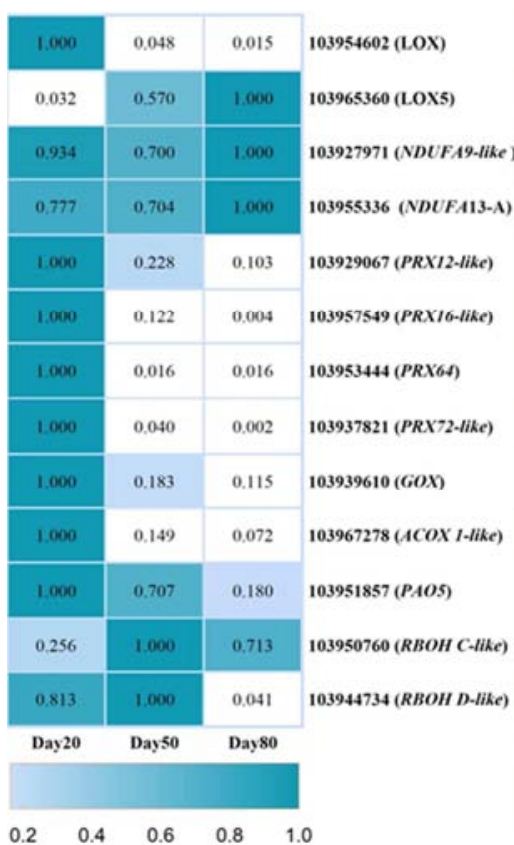

\section{Proteome data}

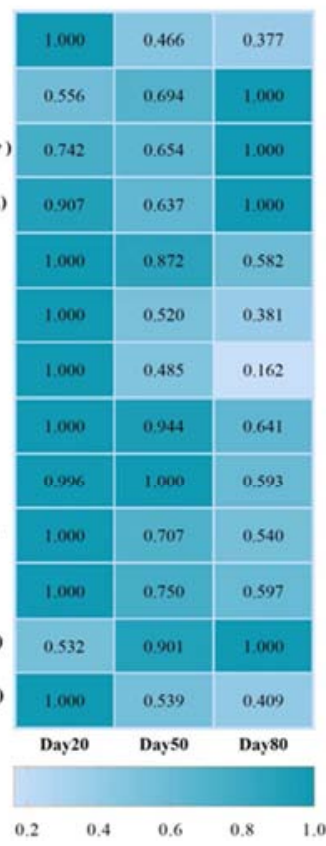

Figure 6. Major DEGs and DAPs related to ROS production in Korla pear pulp during the stone cell differentiation. Heat maps were produced using standardized figures that were transformed to a value between 0.0 and 1.0 by Min-Max normalization method.

\section{Discussion}

Stone cells are one of the characteristic traits of pear fruit. The increasing stone cell content is also one of the important factors affecting pear fruit quality. Studies have shown that stone cells are formed by secondary thickening of parenchyma cell walls that consist of a large amount of lignin, cellulose and hemicellulose $[15,17,18]$. ROS, especially $\mathrm{H}_{2} \mathrm{O}_{2}$ used as an oxidant, plays important roles in oxidative coupling of lignin monomers, and cross-linking between cell wall polymers by diferulic linkages [19-22]. In this work, we have found several genes that encode enzymes (PRX, RBOH, PAO, GLP) responsible for the production of $\mathrm{H}_{2} \mathrm{O}_{2}$ in the cell walls. All 
genes that encode aforementioned apoplastic ROS generating enzymes were abundantly expressed in the early stage, and down regulated in the later stage of fruit development. It is reported that $\mathrm{H}_{2} \mathrm{O}_{2}$ produced by $\mathrm{PAO}, \mathrm{RBOH}, \mathrm{PAO}$ and Germin-like oxalate oxidase is needed for peroxidase-mediated cell wall cross-linking [23-27]. Previously, we found that in Korla pear fruits, differentiation of stone cells mainly occurred during cell division stage of fruit pulps, interestingly the stone cell differentiation period basically overlaps with ROS accumulation and fruit cell apoptosis period [16]. It was reported the transition from cellular proliferation to elongation in the root tissue of Arabidopsis is regulated by ROS homeostasis, in which expanding meristem cells contain higher levels of $\mathrm{O}_{2}^{--}$, while $\mathrm{H}_{2} \mathrm{O}_{2}$ accumulates in the elongation zone [28, 29]. $\mathrm{H}_{2} \mathrm{O}_{2}$ is essential for tracheary element (TE) development [26], its scavenging in cell cultures inhibits the development of secondary cell walls [30-32]. These findings suggest that ROS originating from apoplast may have a crucial role in the stone cell differentiation process.

Peroxisomes provide a rich source of $\mathrm{H}_{2} \mathrm{O}_{2}$ through photorespiratory reaction of GOX [33, 34]. The role of GOX in biotic and abiotic tress resistance reported in several plants [35-39]. Mutant studies in Barley and Arabidopsis showed that cat mutants accumulates high levels of $\mathrm{H}_{2} \mathrm{O}_{2}$, and $\mathrm{H}_{2} \mathrm{O}_{2}$ was generated by peroxisomal GOX can induce cell apoptosis [34, 40-42], all Arabidopsis GOX mutants has the phenotype of dramatic reductions in cell death and $\mathrm{H}_{2} \mathrm{O}_{2}$ level. In accordance with these, in our work, synchronizing with stone cell differentiation period, all of $G O X$ genes showed pick expression in the early stage, and reached the lowest level in the late stage, indicating that GOXs may participate in the process of cell differentiation. In addition, some other genes that encode enzymes regulate ROS generation in peroxisomes (ACX) and during the fatty acid catabolism (LOX) were also differentially expressed during the experimental period. Synchronized with stone cell differentiation period, a $A C O X$ gene (Entrez ID: 103967278) and its correlated protein (protein id: XP_009378830.1) as well as most of the LOXS showed pick expression in the early stage, and reached their lowest points in the late stage. These genes have been reported to play an important role in plant signal transduction and development, especially in jasmonic acid biosynthesis and some stress responses [43-46]. $\mathrm{H}_{2} \mathrm{O}_{2}$ has the ability to diffuse through cellular membranes and manipulate directly the function of cell-to-cell signaling. Though $\mathrm{H}_{2} \mathrm{O}_{2}$ generated by ACOX and LOX may act as a signal molecule to play an essential role in stone cell differentiation. However, the further studies need to be done on the potential roles of these genes in stone cell differentiation process. Interestingly, majority of $A C O X$ genes and some of $L O X$ genes and their proteins showed 2 folds to 100 folds increase in late fruits (80 DAF) in comparison with the early fruits (20 DAF). Fruits from Day 80 were next to maturation, during this period, sugar accumulation and synthesis of aroma substances are triggered to form the unique quality of Korla pear fruits. Both of ACOX and LOX are key enzymes in fatty acid oxidation resulting in the degradation of fatty acid to sugars, and the intermediate products are the precursors of different types of aromatic substances [26, 47-50]. All these results suggest that $A C O X$ and $L O X$ genes showed high expression in late fruits may play essential roles in sugar accumulation and aroma formation during the fruit maturation.

Under normal respiratory conditions some amount of ROS are produced in mitochondria by electron transport chain. But in some stress conditions, such as extreme temperatures, drought, high light and heavy metals, ROS generation in mitochondria is significantly enhanced leading to activation of PCD [51-54]. In our work, we found that expression levels of genes, encoding complex I subunits with the function of NADH driven oxidative dehydrogenation (NDUFV) and electron transportation (NDUFS), in late developmental stage pear fruit were higher than that of in the early stages, while the genes, encoding the subunit proteins with the function of maintaining the structural integrity of complex I, were highly expressed in early stage of fruit development, indicating that the electron transfer efficiency of mitochondrial respiratory chain is low in the early stage, and some electron leakage may occur. The production of mitochondrial ROS is closely related to cell apoptosis. However, in our study expression fold changes of these genes between different developmental stages were not obvious. Therefore, it is speculated that the formation of stone cells at the early stage is essentially the process of developmental programmed cell death ( $\mathrm{dPCD})$, parenchyma cells around the vascular bundles stop growing and differentiate early at cell division stage to form the extension part of original vascular system. Supporting this, the panoramic scanning images of paraffin section from the early stage fruits showed that stone cells were mainly formed around vascular bundles (Figure 7). Intact vascular bundles were observed in the early stage pear fruits, while discontinuous or no vascular tissue was observed in the late fruit cells (Figure 8), indicating that the stone cell formation is more likely the result from the differentiation of parenchyma cells adjacent to the vascular bundles. The genes identified in our study have been reported to be linked to PCD that occurs during TE differentiation or cross-linking between cell wall polymers during the secondary thickening in other species $[26,32,55,56]$. Vascular bundles might be broken as the surrounding parenchyma cells enlarged in size, the fragmented vascular bundles were squeezed together to form the stone cell clusters. As for the increasing stone cells or formation of rough skin fruits in later stage of fruit development, fruit cells may experience unfavorable conditions, and all of these adverse conditions evoke a disturbance in cellular redox homeostasis, and in order to maintain normal growth, stress induced ROS may lead to the differentiation of parenchyma cells around vascular bundles (receptacle vascular bundle) which have the potentials to preferentially differentiate to form part of the vascular bundle. The regulatory function of these genes during the stone cell differentiation process needs to be further investigated. 


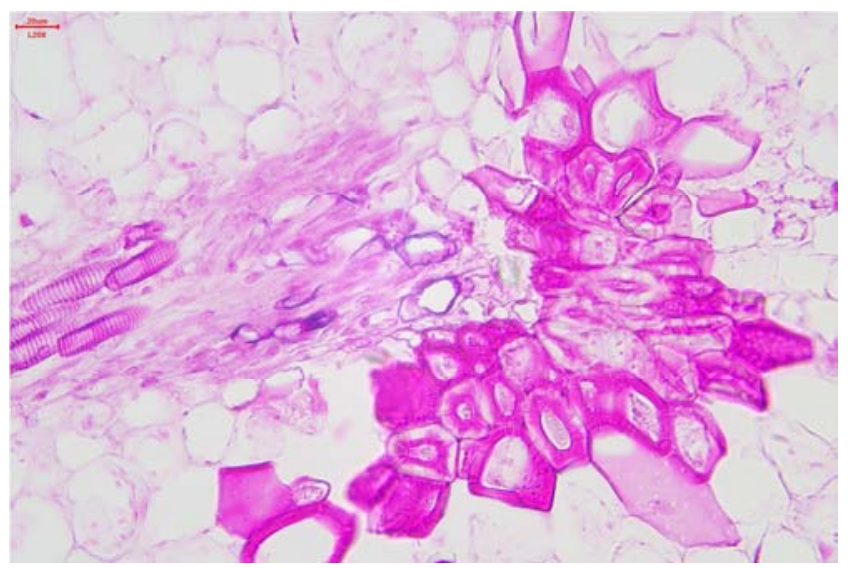

Figure 7. Safranin staining result of stone cells in Korla pear fruit at early development stage.

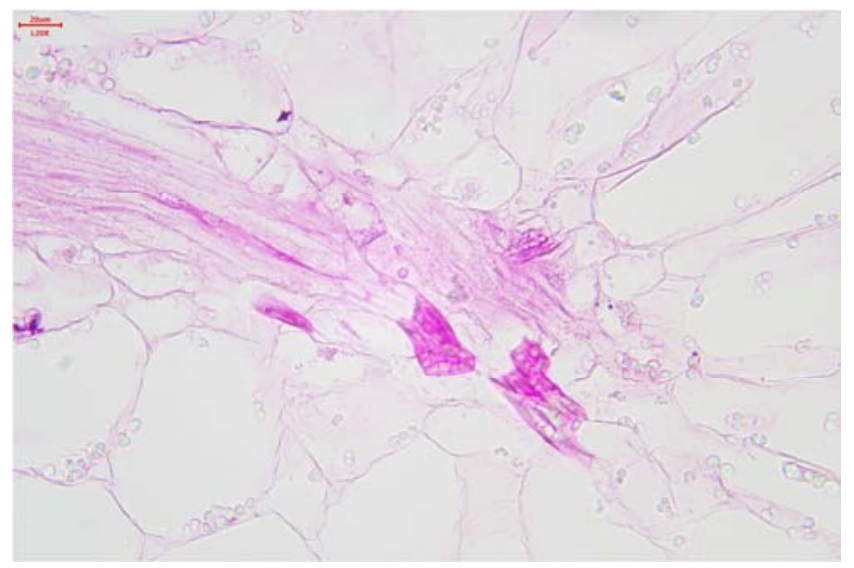

Figure 8. Safranin staining result of stone cells in Korla pear fruit at late development stage.

\section{Conclusion}

The increased stone cell content is one of the major factors that leads to the formation of rough skin on Korla pear fruits. ROS plays important roles in oxidative coupling of lignin monomers, and cross-linking between cell wall polymers. In this work, we identified 74 DEGs and 15 DAPs that relate ROS generation in different cell organelles. Among them, apoplastic ROS related genes and proteins were dominantly expressed during the crucial period of stone cell differentiation, this indicates that apoplast may be the main source of ROS that participate in the process of stone cell differentiation. In addition, peroxisome and fatty acid metabolism pathways also produce certain amount of ROS during this period.

\section{Conflict of Interest}

The authors declare that they have no competing interests.

\section{Acknowledgements}

This research was funded by the Natural Science Foundation of Xinjiang Province (CN) (Grant No. 2019D01A63) and National Natural Science Foundation of
China (Grant No. 31760565). Funders have no role in the design of the study and collection, analysis, and interpretation of data and in writing the manuscript.

\section{References}

[1] Ben-Arie R. and Kislev N. 1979. Ultrastructural changes in the cell walls of ripening apple and pear fruit. Plant Physiology, 64 (2): 197-202.

[2] Arioli T., Peng L., Betzner A. S., Burn J., Wittke W., Herth W., Camilleri C., Hofte H., Plazinski J., Birch R., Cork A., Glover J., Redmond J. and Williamson R. E. 1998. Molecular analysis of cellulose biosynthesis in Arabidopsis. Science, 279 (5351): 717-720.

[3] Yan C., Yin M., Zhang N., Jin Q., Fang Z., Lin Y. and Cai Y. 2014. Stone cell distribution and lignin structure in various pear varieties. Scientia Horticulturae, 174: 142-150.

[4] Barros J., Serk H., Granlund I. and Pesquet E. 2015. The cell biology of lignification in higher plants. Annals of Botany, 115 (7): 1053-1074.

[5] Voxeur A., Wang Y. and Sibout R. 2015. Lignification: different mechanisms for a versatile polymer. Current Opinion in Plant Biology, 23: 83-90.

[6] Huang R., Xia R., Hu L., Lu Y. and Wang M. 2007. Antioxidant activity and oxygen-scavenging system in orange pulp during fruit ripening and maturation. Scientia Horticulturae, 113 (2): 166-172.

[7] Luo Y., Tang H. and Zhang Y. 2011. Production of reactive oxygen species and antioxidant metabolism about strawberry leaves to low temperatures. Journal of Agricultural Science, 3 (2): 89-96.

[8] Sabban-Amin R., Feygenberg O., Belausov E. and Pesis E. 2011. Low oxygen and 1-mcp pretreatments delay superficial scald development by reducing reactive oxygen species (ROS) accumulation in stored 'granny smith' apples. Postharvest Biology and Technology, 62 (3): 295-304.

[9] Pandey V. P., Singh S., Jaiswal N., Awasthi M., Pandey B. and Dwivedi U. N. 2013. Papaya fruit ripening: ROS metabolism, gene cloning, characterization and molecular docking of peroxidase. Journal of Molecular Catalysis B: Enzymatic, 98: 98-105.

[10] Kumar V., Irfan M., Ghosh S., Chakraborty N., Chakraborty S. and Datta A. 2016. Fruit ripening mutants reveal cell metabolism and redox state during ripening. Protoplasma, 253 (2): 581-594.

[11] Lu G., Li Z., Zhang X., Wang R. and Yang S. 2014. Expression analysis of lignin-associated genes in hard end pear (Pyrus pyrifolia Whangkeumbae) and its response to calcium chloride treatment conditions. Journal of Plant Growth Regulation, 34 (2): 251-262.

[12] Li Z., Yang Z. and Wang R. 2017. Relationship between 'hard end' and active oxygen metabolism in "Whangkeumbae" pear fruit. Northern horticulture, 000 (002): 1-6.

[13] Wang H., An Y. and Wang L. 2017. Morphological and anatomic observation on fruit russet formation of pear (Pyrus pyrifolia nakai 'cuiguan'). Journal of Fruit Science, 34 (11): 1415-1425. 
[14] Livak K. J. and Schmittgen T. D. 2001. Analysis of relative gene expression data using Real-Time quantitative PCR and the $2^{-\Delta \Delta \mathrm{CT}}$ method. Methods, 25 (4): 402-408.

[15] Mamat A., Ayup M., Zhang X., Ma K., Mei C., Yan P., Han L. and Wang J. 2019. Pulp lignification in korla fragrant pear. European Journal of Horticultural Science, 84 (5): 263-273.

[16] Mamat A., Zhang X., Ma K., Mei C., Yan P., Han L. and Wang J. 2020. Study on the relationship between the stone cell formation and apoptosis during the fruit development of Korla xiangli pear. Journal of Fruit Sciense, 37 (1): 59-67.

[17] Nie J., Cai Y. P., Zhang S., Lin Y., Xu Y. and Zhang J. Y. 2009. The anatomic study on relationship of stone cells and parenchyma cells during fruit development of Pyrus bretschneideri. Acta Horticulturae Sinica, 36: 1209-1214.

[18] Brahem M., Renard C. M., Gouble B., Bureau S. and Le Bourvellec C. 2017. Characterization of tissue specific differences in cell wall polysaccharides of ripe and overripe pear fruit. Carbohydr Polym, 156: 152-164.

[19] Grabber J. H., Ralph J. and Hatfield R. D. 2000. Cross-linking of maize walls by ferulate dimerization and incorporation into lignin. Journal of Agricultural and Food Chemistry, 48 (12): 6106-6113.

[20] Grabber J. H., Ralph J. and Hatfield R. D. 2002. Model studies of ferulate-coniferyl alcohol cross-product formation in primary maize walls: implications for lignification in grasses. Journal of Agricultural and Food Chemistry, 50 (21): 6008-6016.

[21] Passardi F., Penel C. and Dunand C. 2004. Performing the paradoxical: how plant peroxidases modify the cell wall. Trends in Plant Science, 9 (11): 534-540.

[22] Novo-Uzal E., Fernandez-Perez F., Herrero J., Gutierrez J., Gomez-Ros L. V., Bernal M. A., Diaz J., Cuello J., Pomar F. and Pedreno M. A. 2013. From Zinnia to Arabidopsis: approaching the involvement of peroxidases in lignification. Journal of Experimental Botany, 64 (12): 3499-3518.

[23] Møller S. G. and McPherson M. J. 1998. Developmental expression and biochemical analysis of the Arabidopsis ataol gene encoding an $\mathrm{H}_{2} \mathrm{O}_{2}$-generating diamine oxidase. Plant Journal, 13 (6): 781-791.

[24] Cona A., Cenci F., Cervelli M., Federico R., Mariottini P., Moreno S. and Angelini R. 2003. Polyamine oxidase, a hydrogen peroxide-producing enzyme, is up-regulated by light and down-regulated by auxin in the outer tissues of the maize mesocotyl. Plant Physiology, 131 (2): 803-813.

[25] Cona A., Rea G., Angelini R., Federico R. and Tavladoraki P. 2006. Functions of amine oxidases in plant development and defence. Trends in Plant Science, 11 (2): 80-88.

[26] Tisi A., Federico R., Moreno S., Lucretti S., Moschou P. N., Roubelakis-Angelakis K. A., Angelini R. and Cona A. 2011. Perturbation of polyamine catabolism can strongly affect root development and xylem differentiation. Plant Physiology, 157 (1): 200-215.

[27] Karkonen A. and Kuchitsu K. 2015. Reactive oxygen species in cell wall metabolism and development in plants. Phytochemistry, 112: 22-32.

[28] Tsukagoshi H., Busch W. and Benfey P. N. 2010. Transcriptional regulation of ROS controls transition from proliferation to differentiation in the root. Cell, 143 (4): 606-616.

[29] Wells D. M., Wilson M. H. and Bennett M. J. 2010. Feeling upbeat about growth: Linking ROS gradients and cell proliferation. Developmental Cell, 19 (5): 644-646.

[30] Blokhina O. B., Chirkova T. V. and Fagerstedt K. V. 2001. Anoxic stress leads to hydrogen peroxide formation in plant cells. Journal of Experimental Botany, 52 (359): 1179-1190.

[31] Kotula L., Ranathunge K., Schreiber L. and Steudle E. 2009. Functional and chemical comparison of apoplastic barriers to radial oxygen loss in roots of rice (Oryza sativa L.) grown in aerated or deoxygenated solution. Journal of Experimental Botany, 60 (7): 2155-2167.

[32] Pesquet E., Zhang B., Gorzsas A., Puhakainen T., Serk H., Escamez S., Barbier O., Gerber L., Courtois-Moreau C., Alatalo E., Paulin L., Kangasjarvi J., Sundberg B., Goffner D. and Tuominen H. 2013. Non-cell-autonomous postmortem lignification of tracheary elements in Zinnia elegans. Plant Cell, 25 (4): 1314-1328.

[33] Noctor G., Veljovic-Jovanovic S., Driscoll S., Novitskaya L. and Foyer C. H. 2002. Drought and oxidative load in the leaves of C3 plants: a predominant role for photorespiration? Annals of Botany, 89 (7): 841-850.

[34] Foyer C. H., Bloom A. J., Queval G. and Noctor G. 2009. Photorespiratory metabolism: genes, mutants, energetics, and redox signaling. Annual Review of Plant Biology, 60: 455-484.

[35] Bohman S., Wang M. and Dixelius C. 2002. Arabidopsis thaliana-derived resistance against Leptosphaeria maculans in a Brassica napus genomic background. Theoretical and Applied Genetics, 105 (4): 498-504.

[36] Schäfer P., Hückelhoven R. and Kogel K. H. 2004. The white barley mutant Albostrians shows a supersusceptible but symptomless interaction phenotype with the hemibiotrophic fungus Bipolaris sorokiniana. Molecular Plant-Microbe Interactions, 17 (4): 366-373.

[37] Taler D., Galperin M., Benjamin I., Cohen Y. and Kenigsbuch D. 2004. Plant $e R$ genes that encode photorespiratory enzymes confer resistance against disease. Plant Cell, 16 (1): 172-184.

[38] Rojas C. and Mysore K. S. 2012. Glycolate oxidase is an alternative source for $\mathrm{H}_{2} \mathrm{O}_{2}$ production during plant defense responses and functions independently from NADPH oxidase. Plant Signaling \& Behavior, 7 (7): 752-755.

[39] Sewelam N., Jaspert N., Van Der Kelen K., Tognetti V. B., Schmitz J., Frerigmann H., Stahl E., Zeier J., Van Breusegem F. and Maurino V. G. 2014. Spatial $\mathrm{H}_{2} \mathrm{O}_{2}$ signaling specificity: $\mathrm{H}_{2} \mathrm{O}_{2}$ from chloroplasts and peroxisomes modulates the plant transcriptome differentially. Molecular Plant, 7 (7): 1191-1210.

[40] Kendall A. C., Keys A. J., Turner J. C., Lea P. J. and Miflin B. J. 1983. The isolation and characterisation of a catalase-deficient mutant of barley (Hordeum vulgare L.). Planta, 159 (6): 505-511.

[41] Smith I. K., Kendall A. C., Keys A. J., Turner J. C. and Lea P. J. 1984. Increased levels of glutathione in a catalase-deficient mutant of barley (Hordeum vulgare L.). Plant Science Letters, 37 (1-2): 29-33. 
[42] Chaouch S. and Noctor G. 2010. Myo-inositol abolishes salicylic acid-dependent cell death and pathogen defence responses triggered by peroxisomal hydrogen peroxide. New Phytologist, 188 (3): 711-718.

[43] Kondo S., Setha S., Rudell D. R., Buchanan D. A. and Mattheis J. P. 2005. Aroma volatile biosynthesis in apples affected by 1-mcp and methyl jasmonate. Postharvest Biology and Technology, 36 (1): 61-68.

[44] Vanacker H., Sandalio L., Jimenez A., Palma J. M., Corpas F. J., Meseguer V., Gomez M., Sevilla F., Leterrier M., Foyer C. H. and del Rio L. A. 2006. Roles for redox regulation in leaf senescence of pea plants grown on different sources of nitrogen nutrition. Journal of Experimental Botany, 57 (8): 1735-1745.

[45] Mosblech A., Feussner I. and Heilmann I. 2009. Oxylipins: structurally diverse metabolites from fatty acid oxidation. Plant Physiology and Biochemistry, 47 (6): 511-517.

[46] Zhou G., Ren N., Qi J., Lu J., Xiang C., Ju H., Cheng J. and Lou Y. 2014. The 9-lipoxygenase Osr9-LOX1 interacts with the 13-lipoxygenase-mediated pathway to regulate resistance to chewing and piercing-sucking herbivores in rice. Plant Physiology, 152 (1): 59-69.

[47] Leone A., Bleve-Zacheo T., Gerardi C., Melillo M. T., Leo L. and Zacheo G. 2006. Lipoxygenase involvement in ripening strawberry. Journal of Agricultural and Food Chemistry, 54 (18): 6835-6844.

[48] Montero-Prado P., Rodriguez-Lafuente A. and Nerin C. 2011. Active label-based packaging to extend the shelf-life of "calanda" peach fruit: Changes in fruit quality and enzymatic activity. Postharvest Biology and Technology, 60 (3): 211-219.

[49] Xi W. P., Zhang B., Liang L., Shen J. Y., Wei W. W., Xu C. J.,
Allan A. C., Ferguson I. B. and Chen K. S. 2012. Postharvest temperature influences volatile lactone production via regulation of acyl-CoA oxidases in peach fruit. Plant Cell and Environment, 35 (3): 534-545.

[50] Vogt J., Schiller D., Ulrich D., Schwab W. and Dunemann F. 2013. Identification of lipoxygenase (LOX) genes putatively involved in fruit flavour formation in apple (Malus $\times$ domestica). Tree Genetics \& Genomes, 9 (6): 1493-1511.

[51] Nawkar G. M., Maibam P., Park J. H., Sahi V. P., Lee S. Y. and Kang C. H. 2013. Uv-induced cell death in plants. International Journal of Molecular Sciences, 14 (1): 1608-1628.

[52] Vanlerberghe G. C. 2013. Alternative oxidase: a mitochondrial respiratory pathway to maintain metabolic and signaling homeostasis during abiotic and biotic stress in plants. International Journal of Molecular Sciences, 14 (4): 6805-6847.

[53] Liu J., Li Z., Wang Y. and Xing D. 2014. Overexpression of ALTERNATIVE OXIDASE1a alleviates mitochondria-dependent programmed cell death induced by aluminium phytotoxicity in Arabidopsis. Journal of Experimental Botany, 65 (15): 4465-4478.

[54] Petrov V., Hille J., Mueller-Roeber B. and Gechev T. S. 2015. ROS-mediated abiotic stress-induced programmed cell death in plants. Frontiers in Plant Science, 6: 69.

[55] Kaurilind E., Xu E. and Brosche M. 2015. A genetic framework for $\mathrm{H}_{2} \mathrm{O}_{2}$ induced cell death in Arabidopsis thatiana. BMC Genomics, 16 (1): 837.

[56] Corpas F. J., Barroso J. B., Palma J. M. and Rodriguez-Ruiz M. 2017. Plant peroxisomes: a nitro-oxidative cocktail. Redox Biology, 11: 535-542. 